\title{
A CULTURA E A ARTE NO COTIDIANO ESCOLAR
}

\author{
CULTURE AND ART IN SCHOOL LIFE
}

\begin{abstract}
Ana Karina de Moura
Secretaria Municipal de Educação de Barra do Bugres, MT, Brasil. E-mail: anakmoura11@gmail.com
\end{abstract}

\section{Laine Marques dos Santos Almeida Bertáo}

Prefeitura Municipal de Barra do Bugres, Mato Grosso, MT, Brasil. E-mail: laine.marques.bertao@ gmail.com

\author{
Maria Luiza Barreto \\ Secretaria do Estado de Educaçáo do Mato Grosso, Barra do Bugres, MT, Brasil. E-mail: \\ barretomarialuiza47@gmail.com
}

DOI: https://doi.org/10.46550/amormundi.v2i8.136

Recebido em: 10.11.2021

Aceito em: 30.12.2021

\begin{abstract}
Resumo: Por meio do trabalho pedagógico em que se preza pela abordagem da cultura e da arte, é possível uma ressignificação da realidade, uma vez que a troca de experiências que ocorre no ambiente escolar manifesta que cada indivíduo compreende a mesma coisa de maneira diferente, construindo o próprio conhecimento e seu ponto de vista sobre cada situação. Sem dúvida, a cultura e a arte são consideradas mediadoras do conhecimento, permitindo que todos os indivíduos envolvidos nas trocas de experiências, por elas proporcionadas, construam uma aprendizagem enriquecedora e criativa. Logo, a cultura e a arte são meios de expressão da própria realidade. Elas não exprimem apenas o que se vê ou o que se pensa, mas o que ela realmente é: sua vitalidade, sua força, sua fraqueza, seus medos, seus sonhos, suas vontades, suas dúvidas, seus conflitos, seu temperamento e seu caráter, por exemplo. Sendo então, as mais completas formas de expressão do ser humano, desenvolvendo o pensamento, a percepção, a sensibilidade, a cognição e a intuição. Assim, por meio da revisão bibliográfica, o objetivo geral desse artigo buscou abordar a relevância da cultura e da arte no contexto escolar. E, a partir de entáo, chegouse à conclusão que tais elementos contribuem significativamente para o processo de aprendizagem da criança.
\end{abstract}

Palavras-chave: Cultura. Arte. Aprendizagem.

Abstract: Through the pedagogical work that values the approach to culture and art, a redefinition of reality is possible, since the exchange of experiences that takes place in the school environment shows that each individual understands the same thing in a different way, building the own knowledge and their point of view on each situation. Without a doubt, culture and art are considered mediators of knowledge, allowing all individuals involved in the exchange of experiences they provide to build enriching and creative learning. Therefore, culture and art are means of expressing reality itself. They express not only what one sees or what one thinks, but what it really is: its vitality, its strength, its weakness, its fears, its dreams, its desires, its doubts, its conflicts, its temperament and its character, for example. Therefore, they are the most complete forms of human expression, 
developing thought, perception, sensitivity, cognition and intuition. Thus, through the literature review, the general objective of this article sought to address the relevance of culture and art in the school context. And, from then on, it was concluded that these elements significantly contribute to the child's learning process.

Keywords: Culture. Art. Learning.

\section{Introduçáo}

o contexto atual, a interdisciplinaridade se faz necessária no âmbito escolar, uma
vez que a educaçáo precisa desenvolver cidadáos críticos, reflexivos e participativos, capazes de intervirem na sua realidade para o desenvolvimento de uma sociedade mais justa e igualitária. Além do mais, essa combinação reforça os pilares culturais formadores, influenciando significativamente na visão de mundo e no conceito artístico de um indivíduo ainda na infância.

Por isso, a educação se preocupa em contribuir para a formação integral de um indivíduo, onde as trocas sociais acontecem rapidamente através das diversas culturas, da leitura, da escrita, da linguagem oral e visual. E, a escola busca reconhecer e desenvolver na criança as competências de aprendizagem, como a leitura e escrita. Nesse sentido, a literatura é considerada como uma atividade que educa, diverte, ensina e prepara a criança para a vida em sociedade por meio de contos, fábulas, lendas, gravuras, fantoches, dobraduras, entre outros.

Sem dúvida, a arte é elemento de importância no cotidiano escolar e, por isso, deve estar presente em sala de aula como uma forma de representação da linguagem, sendo uma maneira criativa de importar a realidade. Além disso, a arte deve extrapolar as dimensóes da escola ultrapassando a teoria do pensamento artístico e possibilitando a exploraçáo de cada aspecto que contribui para a formação do indivíduo. A partir disso, a cultura e suas características, seus padrões, valores, normas, ideias e objetivos, são transmitidos e reforçados para as geraçóes, estabelecendo atitudes e valores.

Assim, considerando que a cultura e a arte permitem ao ser humano a oportunidade de se conhecer como também de demonstrar seus sentimentos e pensamentos, este artigo tem por finalidade abordar a relevância do professor pedagogo para a trajetória de mobilização dos conhecimentos relacionados à cultura e à arte no cotidiano escolar e a importância de relacionar tais práticas com a ludicidade e o processo de alfabetização e letramento dos alunos, ressaltando a interdisciplinaridade no processo educativo.

\section{Metodologia}

No campo cientifico, uma pesquisa segue um percurso metodológico na intenção de investigar um determinado assunto. Assim, esse artigo utilizou como metodologia a pesquisa bibliográfica, uma vez que se fez necessário realizar um levantamento de dados acerca do tema relacionado à cultura e a arte no cotidiano escolar. Para Mattar (1999) a pesquisa bibliográfica inclui a busca por informaçóes em publicaçôes gerais (jornais e revistas), governamentais (documentos publicados pelos governos federal, estadual e municipal) e institucionais (ligadas a instituiçóes de pesquisa, universidades e organizações não-governamentais).

De acordo com Vergara (2007), uma pesquisa refere-se a coleta de informaçóes para 
um estudo sistematizado desenvolvido com base no levantamento de material publicado em material impresso e/ou digital. Essa característica, leva ao método da pesquisa, que nessa proposta correspondeu à pesquisa bibliográfica por conta da fundamentação teórica que se construiu, tendo como principal característica "explorar por meio de diferentes autores a essência de um determinado assunto” (LAKATOS, 2007, p. 107).

Além disso, conforme apresenta Zanella (2013) é necessário definir a abordagem que um estudo terá, podendo ser de caráter quantitativo ou qualitativo. Assim, para viabilizar o levantamento de informaçóes e a elaboração da proposta desse artigo científico, adotou-se a abordagem qualitativa, utilizando-se de estudos de casos e artigos anteriores sobre a cultura e a arte no cotidiano escolar. Todo o estudo e construção da produção textual aconteceu entre no primeiro semestre do ano de 2022.

\section{Referencial teórico}

\subsection{A importância da arte e da literatura infantil no ambiente escolar}

O conceito de arte remonta aos primórdios da humanidade e nas inúmeras formas de organização da sociedade. De modo geral, percebe-se que a arte está intimamente relacionada com as sensaçôes e emoções dos indivíduos, pelo qual ele se expressa. Assim, a arte faz parte de todos os momentos da existência humana, tendo forte representatividade na trajetória educacional de um indivíduo. Segundo Aidar (2010), a arte tem uma importante função social a medida que expóe características históricas e culturais de determinada sociedade, tornando-se um reflexo da essência humana.

Kishimoto (1999) define arte como a capacidade que leva o indivíduo a diversas e constantes reflexôes ao longo da vida, sendo expressa de modos nem sempre explícitos. Desse modo, percebe-se a arte como elemento fundamental no cotidiano escolar, uma vez que incentiva as expressóes corporais por meio de jogos e brincadeiras, além de possibilitar pensamentos e açôes criativas. Com isso, vê-se que o fazer arte na educação caracteriza-se pela possibilidade de dar vazão à liberdade do aluno, incentivando que o mesmo se expresse por meio de inúmeros atos, como: a pintura, artesanato, dança e encenação, por exemplo.

Convém salientar que, ao passo que a criança se expressa artisticamente passa a contemplar diversos aspectos culturais do meio em que vive, ultrapassando o limite da teoria do pensamento criativo. E, nesse momento, conforme aponta Rios e Silva (2018), é possível observar o valor da interdisciplinaridade, uma vez que a arte esbarra em outros preceitos fundamentais para o processo de aprendizagem e construção de conhecimento de uma criança. Em outras palavras, compreende-se que atitudes, valores e concepçóes são ressignificadas por meio da arte, valorizando, assim, a troca de experiências.

Sem dúvida, nessa perspectiva de ressignificação artística, a literatura infantil torna-se uma valiosa aliada de aquisição cultural. Diante disso, é possível considerar a literatura infantil como uma das principais fontes de informação atrelada ao desenvolvimento da criança, proporcionando situaçôes de imaginação, fantasia e criatividade. Condurú e Santos (2018) comentam que o contato com o universo literário dá ao indivíduo a oportunidade de explorar sua criatividade e imaginação. E, no universo infantil, uma maneira de explorar essas possibilidades é por meio 
do momento de contação de histórias, por exemplo, isso porque é o momento em que se busca promover a interação e instigar a imaginação do indivíduo.

Logo, se percebe a importância da arte e da literatura infantil no cotidiano escolar, promulgando açôes que instigam a educação em sentido amplo e integral, representando tudo aquilo que pode ser feito para desenvolver o ser humano e, no sentido estrito, representando a instrução e o desenvolvimento de competências e habilidades diversas. Além disso, a integração existente entre os conhecimentos pautados na cultura e na literatura infantil é apresentada pela Base Nacional Comum Curricular (BNCC, 2018) ao indicar que a educação é a promoção do desenvolvimento de crianças e jovens em todas as suas dimensôes: intelectual, física, emocional, social e cultural, com a finalidade de expandir as múltiplas capacidades humanas.

Considerando a importância da arte e literatura ao desenvolvimento escolar da criança, afirma-se que os alunos devem encontrar ambientes escolares propícios à aprendizagem significativa, cabendo ao educador atentar-se às necessidades e talentos de seus discentes. E com isso, criar açôes que potencializem as práticas pedagógicas dentro de um contexto lúdico e descontraído. Assim, é notório que a educação deve sempre se preocupar em contribuir para a formação integral de um indivíduo, onde as trocas sociais acontecem rapidamente através das diversas culturas, da leitura, da escrita, da linguagem oral e visual.

No que se refere à leitura literária, esta tem por finalidade adaptar o crescimento educacional do aluno, possibilitando o acesso a diversos contextos culturais e sociais, enriquecendo o vocabulário, motivando uma escrita mais precisa e possibilitando o estímulo imaginário. Nesse sentido, "a leitura é um processo de representação, uma vez que a leitura não se dá por acesso direto à realidade, mas por intermédio de elementos. Portanto, ler é reconhecer o mundo através de espelhos" (LEFFA, p. 10, 1996).

Com isso, a leitura literária surge como uma transformação que reflete o que cada indivíduo tem acumulado em sua memória e consegue expressar, a partir de seus conhecimentos prévios e o que isto representa para ele. Em outras palavras, Villardi (1997) ressalta que ler é construir uma concepção de mundo, analisando e posicionando-se criticamente frente às informaçóes captadas por meio do que se lê, permitindo, assim, exercer a cidadania de modo mais abrangente.

Seguindo a mesma linha de pensamento, Freire (1995) define a literatura infantil como o ato de imaginar e captar todas as possibilidades ao entorno da criança, de modo prazeroso e conquistador, no qual o aluno tenha a possibilidade de fazer escolhas e optar por aquilo que mais lhe cativa. Sendo assim, na proposta da literatura nos anos iniciais do ensino fundamental é imprescindível que haja finalidades específicas, com foco no crescimento intelectual e social do aluno, para que o processo de formar leitores possa se propagar nos anos seguintes, e que esse processo seja contínuo e crescente, de forma que se torne um hábito prazeroso.

Ao se perceber a relevância da arte e da literatura infantil no ambiente escolar, alguns cuidados são necessários por parte do educador no que se refere às estratégias e ferramentas a serem implementadas nos anos iniciais do ensino fundamental da educação básica. Nesse sentido, Rios e Silva (2018) comentam que as atividades lúdicas podem ser utilizadas de forma multidisciplinar, no sentido de motivar e despertar o interesse das crianças para a construção do conhecimento. Isso porque, a ludicidade visa estimular os conhecimentos prévios dos alunos e facilitar a aquisição de novas habilidades, e isso pode facilmente ser associado ao desenvolvimento literário do aluno. 
Nessa perspectiva, a ludicidade torna-se um recurso pedagógico insubstituível, que pode ser usada como estímulo no processo de aprendizagem e na progressão das diferentes habilidades humana, além do mais, é uma importante ferramenta de progresso e alcance de objetivos educacionais. Sobre isso, Almeida (2003) menciona que as práticas lúdicas tem papel fundamental na vida de uma criança, proporcionando momentos de prazer, entrega e dedicaçáo e é no momento das atividades lúdicas que ela expressa e desenvolve habilidades, intelectuais, motoras e sensoriais. Ou seja, é no momento de experiência lúdica que a criança descobre o mundo ao seu redor e formas de lidar com ele.

Segundo Weischelbaum (2017), o repertório musical é uma das práticas mais desenvolvidas entre músicos e estudantes, se comparada à execução vocal e instrumental e mesmo a composição. Trazendo isso para a realidade educacional, cita-se o repertório musical como uma das várias ferramentas lúdicas que possibilitam a inserção da arte e da literatura no ambiente escolar.

Do ponto de vista pedagógico, Torres (2017) sugere que antes da escolha musical é preciso identificar os elementos a contemplar nos processos de escuta e quais são as formas de trabalhá-los; realizar a escuta musical coletiva; identificar os instrumentos musicais e suas famílias; leitura e discussões direcionadas e permitir a participação dos alunos na escolha. Além disso, o autor supracitado afirma que tais etapas contribuem para a escolha adequada de músicas e promove a participação das crianças em todo o processo de aprendizagem, explorando o interesse e compromisso delas com a proposta.

Cabe enfatizar também que, a musicalidade possibilita a articulação de algumas práticas ao processo de ensino e de aprendizagem de modo interdisciplinar, uma vez que a música dá proeminência aos inúmeros aspectos culturais e linguísticos existentes, como a ampliação do repertório artístico do educando. E, sendo considerada múltipla, a arte proporciona a constituição de novos e importantes saberes. Sobre isso, SANTOS (2000, p. 144) afirma que "existem capacidades fundamentais para o desenvolvimento de habilidades [dos alunos] que irão impactar na sua vida adulta, principalmente no universo artístico”.

Portanto, se faz necessário que a escola busque resgatar os valores artísticos intrínsecos e inerentes à infância, como ato de prazer e requisito para emancipação social, promoção da cidadania e resgate cultural. E, ao educador incumbe-se a responsabilidade de traçar e executar estratégias pedagógicas que contemplem o desenvolvimento intelectual, o amadurecimento emocional e a visão crítica do aluno.

\section{Consideraçóes finais}

O modelo educacional atual torna imprescindível interligar as diferentes áreas do conhecimento, utilizando estratégias pedagógicas inovadoras e significativas, afim de proporcionar o interesse, o compromisso e a disposição do indivíduo em aprender. Nesse sentido, os elementos artísticos e literários somam-se às práticas pedagógicas educativas com a proposta de proporcionar desde a infância o contato com a cultura e a linguagem. Por isso, a integração de conteúdos na educação é uma prática que vem sendo difundida amplamente, a partir de concepçóes e discussóes no meio docente e em momentos de reflexão.

Mediante o exposto, percebe-se que a arte e a literatura infantil são ferramentas imprescindíveis no processo de construção do conhecimento da criança. E, além de tal 
importância, cabe ressaltar que essa vertente do conhecimento se propóe como base para o desenvolvimento intelectual e social do indivíduo. Mas para isso, se faz necessário que a criança tenha acesso a obras literárias condizentes com a sua faixa etária. E assim, por meio de constantes incentivos, o educando constrói por si mesmo sua visão crítica de sociedade.

Portanto, despertar no aluno o interesse e gosto pela arte e literatura, a fim de possibilitar seu aprendizado e desenvolver uma visão crítica quanto as áreas do conhecimento, muito depende da maneira com que esse indivíduo é exposto às situações de ensino-aprendizagem. Por isso, afirma-se que as práticas lúdicas desse podem contribuir sobremaneira nesse processo de desenvolvimento educacional dos alunos, explorando a criatividade, imaginação, senso crítico e compreensão de mundo por meio de atividades prazerosas e autônomas.

\section{Referências}

AIDAR, Laura. O que é arte? Disponível em: <https://www.todamateria.com.br/o-que-earte/>. Acesso em: 05, jan, 2022.

ALMEIDA, Paulo Nunes de. Educação lúdica: Técnicas e jogos pedagógicos. $11^{a}$ edição. São Paulo: Loyola, 2003.

BRASIL. Base Nacional Comum Curricular. Brasília: MEC/SEF, 2018.

CONDURÚ, Marise Teles; SANTOS, Ana Cristina da Silva. A contribuiçáo da literatura infantil no desenvolvimento da criança: um estudo de caso no Projeto Literatura da Biblioteca do SESC Maranháo/MA. Disponível em: <https://doi.org/10.26512/rici.v11. n2.2018.8335>. Acesso em: 05, jan, 2022.

FREIRE, Paulo. Política e educaçáo: ensaios. São Paulo: Cortez, 1995.

KISHIMOTO, T.M. Jogo, brinquedo, brincadeira e a educaçáo. São Paulo: Cortez, 1999.

LEFFA, V. J. Aspectos da leitura: uma perspectiva psicolinguística. Coleção Ensaios. Porto Alegre: Sagra, 1996.

MATTAR, F. N. Pesquisa de marketing: metodologia, planejamento. 5. ed. São Paulo: Atlas, 1999.

RIOS, Pedro Paulo Souza; SILVA, Thaynara Oliveira da. O lúdico nas séries iniciais do ensino fundamental: A brincadeira deve continuar. Disponível em: < file:///E:/Usuario/ Downloads/1581014009505\%20(1).pdf>. Acesso em: 05, jan, 2022.

SANTOS, V. C. de F. F. A organizaçáo do espaço para o brincar na educaçáo infantil numa perspectiva histórico-cultural. Disponível em: <http://www.fateb.br/fateb.cientifica/ downloads/1a_edicao/artigos/009_a_organizacao_do_espaco_para_o_brincar_na_educacao_ infantil.pdf>. Acesso em: 05, jan, 2022.

TORRES, Maria Cecília de Araújo Rodrigues. Que músicas escolher para um CD? Seleção e organização de repertório para a aula de música na escola. Londrina, 2017.

VERGARA, Sylvia Constant. Projetos e Relatórios de Pesquisa em Administração. São Paulo: Atlas, 2007. 
VILLARDI, Raquel. Ensinando a gostar de ler: formando leitores para a vida inteira. Rio de Janeiro: Qualitymark, 1997.

WEISCHELBAUM, Anete. Apreciação musical: fundamentos teórico-metodológicos. Curitiba: Editora CRV, 2017.

ZANELLA, Liane Carly Hermes. Metodologia de pesquisa. 2. ed. reimp. Florianópolis: Departamento de Ciências da Administração/UFSC, 2013. 